\title{
Discurso de agradecimento pela outorga do título de Professor Emérito
}

\section{Dilza Atta}

Eu atravesso as coisas e no meio da travessia não vejolsó estava era entretido na ideia dos lugares de saída e de chegada. Assaz o senhor sabe: a gente quer passar um rio a nado e passa; mas vai dar na outra banda é num ponto bem diverso do que em que primeiro se pensou. Digo: o real não está na saída nem na chegada: ele se dispõe para a gente é no meio da travessia

Guimarães Rosa

É muito grata aos cronistas da vida a metáfora do rio que Guimarães Rosa tantas vezes põe na fala de Riobaldo, em Grande Sertão Veredas.Tomo-Ihe emprestada, hoje, a metáfora, para começar essa conversa, uma conversa entre companheiros que, vida afora, menos preocupados com o ponto de saída ou de chegada, tentaram encontrar o real no meio da travessia.

E começo, agradecendo. Ao Dr Edvaldo Boaventura, proponente deste título e autor da saudação a mim dirigida, neste momento de lembranças e de emoção; ao meu departamento; à Faculdade de Educação e a sua DD Diretora, Profa. Iracy Picanço, aos conselhos superiores da UFBA, ao Magnífico Reitor, Prof. Heonir Rocha

A honra.Senhor Reitor, que a Universidade Federal da Bahia me confere, com a outorga do título de Professor Emérito, tem um significado muito especial e transcende o outorgado, isto é, vai além de mim e atinge uma geração de professores que, no seio da universidade, assumiu um compromisso coletivo com a instituição, em detrimento, muitas vezes, de seus problemas pessoais, e soube fazer da Faculdade de Educação, que se ia afirmando, um centro de resistência e de inventividade. E é em nome dessa geração presente nesta sala, disponível ao nosso olhar, ou ao nosso afeto e a nossa saudade - e aqui eu falo de Juscelino, Arapiraca, Judith, Expedito, Carlos Alberto, Eugenia Lúcia, é em nome dessa geração que eu recebo o título e é em seu nome o meu agradecimento.

Essa geração que começou a deixar a Universidade no início dos anos noventa, a ela chegou no início da década de setenta, quando a Faculdade de Educação foi criada.

Era um tempo difícil.Vivia-se a perplexidade de uma luta política que fez desaparecer tantos de nossos companheiros, mas na qual crescemos todos e tentamos amadurecer. Naquele momento, a femínização da educação, provocada pelo aviltamento salarial e por supressão de outras condições de trabalho, que já caracterizava o então ensino de primeiro e de segundo grau, chegava ao ensino superior, no espaço criado pelas Faculdades de Educação. E a mulher consolidava o exercício de sua dupla função - em casa e fora dela, muitas desenvolvendo ainda o conflito por não estarem cumprindo, satisfatoriamente, a finalidade para a qual foram educadas, ainda nas Mercês, na Soledade, nas Sacramentinas, tendo de deixar casa, marido e filhos para cumprir, fora de casa, sua outra função social. Era também o momento da profissionalização, dos mestrados feitos na própria escola, sem dispensa de horas de trabalho, sacrificando-se o professor para não pre- 
judicar nem os estudos, nem a preparação das aulas e demais atividades a serem desenvolvidas com os alunos.

Mas essa foi uma geração privilegiada. Vivera a luta política, inclusive em greves que a retemperaram; e assumira sacrifícios incontestes. Mas vivenciava uma cidade acolhedora, onde não se enfrentava, ainda, a violência explícita que as circunstâncias político-econômicas já gestavam. E recebera também uma Universidade criadora de beleza, uma universidade de concertos, espetáculos de dança e de teatro, fóruns de cinema, exposições de arte, enquanto, fora dela, a poesia invadia a música popular, por vezes, com o teatro, únicos canais de protesto e afirmação de uma postura libertária. E essa geração teve o privilégio de poder usar todo esse acervo de experiências diferentes como matéria prima de suas relações com os alunos,seja nas aulas,seja na incipiente pesquisa, seja nos programas de extensão.

Sinto-me tentada a usar uma categoria de análise atual - os saberes docentes, indicados como o saber da experiência, o saber pedagógico e o saber do conhecimento - para focar melhor meu olhar sobre o objeto da atividade académica de minha geração, de início apenas docência, e ousar avaliá-la, enquanto me avalio a mim mesma. Inseparáveis no momento da atuação do professor em sala de au(a,discriminam-se aqui para efeito de um melhor entendimento.

E eu me arriscaria a afirmar que soubemos usar o saber da experiência, que trazíamos de outras instituições, onde já trabalhavamos, começando a construir um saudável processo de troca nos sistemáticos encontros semanais, promovidos por inspiração da Profa Leda Jesuíno, na Faculdade recém-criada. Muitos estavam vindo dos Colégios de Aplicação da própria UFBAe da Universidade Católica, do Colégio Santa Bernadete ou das classes do CECIBA, onde projetos educacionais avançados se realizavam nos ainda ensinos primário e médio. Outros vinham da Secretaria de Educação do Estado que vivia um momento de reformas criativas sob a coordenação do Prof. Navarro de Brito. Todos se sentiam muito mobilizados pelos problemas educacionais e se empenhavam em traduzir, para a nova instituição, as aprendizagens anteriores. $\mathrm{E}$ o saber da experiência foi ainda enriquecido por aquelas oportunidades culturais às quais todos tínhamos acesso. Essa geração não se negou a expor-se e a trocar com os alunos a vida, em geral, intensamente vivida.

Soubemos usar, também, o saber pedagógico, descobrindo formas de chegar perto do estudante, algumas vezes, apenas através de técnicas modernas de condução do ensino,assunto muito do agrado do tecnicismo que marcara o período; mas, em outros casos, com o emprego de mediação mais profunda da aprendizagem, sobretudo criando ocasiões propícias para instalar-se uma reflexão sobre a prática de que muitos deles eram portadores. Trabalhadores na área de Educação, esses alunos buscaram a nova Faculdade como uma possibilidade de sistematizar as descobertas do dia-a-dia, desenvolvidas, às vezes, solitariamente, sem interlocução. Tal reflexão conduzia a reformulações em suas atividades, enquanto professores e técnicos de educação e, seguramente, era um rico momento de aprendizagem para o professor universitário,que se distanciara da escola de primeiro e de segundo grau, para a qual passou a voltar-se em seus primeiros trabaIhos de pesquisa e de extensão.

É preciso tratar ainda do terceiro nível do saber da docência que os teóricos têm apontado: é o saber do conhecimento, por vezes o único de que se tem consciência, na regência de classe.

Fragmentado nas diversas disciplinas do currículo, nem sempre 
ele se relacionava, no nosso trabalho, com o seu objetivo final: a sala de aula do então primeiro e do segundo grau. Aí, os alunos da escola pública e democrática, uma de nossas bandeiras de luta nos embates políticos, esperavam professores que atendessem a sua demanda de aprendizagem dos conteúdos que tinham de dominar até por questão de sobrevivência, sem falar no seu pleno direito a instrumentos que lhes permitiriam um melhor exercício da cidadania. Convivemos com a ampliação de ofertas de vagas nas escolas públicas. Não se pode negar a democratização do acesso. Mas se deve insistentemente cobrar a democratização da qualidade, isto é, o direito da criança da escola pública ao domínio do que é necessário para a superação do processo de exclusão que tem sido fortalecido na passagem pela própria escola.

E aqui, ouso dizer que a nossa geração, embora tenha dado ao desenvolvimento da Faculdade contribuições muito importantes tais como um esforço na implantação do trabalho coletivo, a aceitação da participação dos alunos nas aulas, na pesquisa e na extensão em um nível de troca efetiva, a tendência a refletir sobre a prática e procurar a avançar a partir dos pontos encontrados, apesar disso, a nossa geração tem uma dívida com o povo.

Em primeiro lugar, por não haver posto a sala de aula, logo as relações professor/aluno, como foco de nosso trabalho. Enquanto canalizamos nossas energias ou em torno da organização do trabalho da escola, pensando nos conhecimentos que formavam a supervisão dos docentes e a orientação educacional dos alunos ou em torno das formas de ensinar a ensinar os conhecimentos básicos, muitas vezes a alunos universitários que pouco dominavam tais conhecimentos, quase abandonamos as reflexões sobre alfabetização, sobre a construção dos mecanismos de aquisição da leitura-escrita, sobre a educação de adultos, sobre a sala de aula como espaço multidiferenciado e as relações que ai se tecem, sobre o uso do espaço e do tempo nas atividades escolares, sobre as relações professor/alunos e as suas implicações para a aprendizagem, sobre a realidade pluricultural de nossas escolas e assim por diante. Evidentemente, o locus de tais reflexões é a Faculdade de Educação e algumas, no país, já desenvolviam estudos nesse caminho, chegando a certas sínteses com resultados aplicados, como experiência, em alguns sistemas municipais

Em segundo lugar, por não havermos mantido as poucas investidas contra a fragmentação dos conhecimentos curriculares, enfatizando trabalhos coletivos integrados que deveriam desenvolver-se a partir da escola, a partir da prática da sala de aula.

E mais ainda, por não termos tido a coragem de inovar na reforma curricular cuja proposta tivemos oportunidade de iniciar. Mais uma vez, a sala de aula, em sua multirreferencialidade, seria o ponto de partida e o ponto de chegada, nessa busca da melhoria da preparação do professor necessário aos alunos da escola pública.

Por acompanhar, ainda que a distância, o trabalho da Faculdade de Educação, sei que pesquisas e projetos de extensão hoje se debruçam sobre esses pontos e atendem a essa demanda. Quanto a nós, em verdade, contribuímos muito pouco para identificar que qualidade nova é criada pela presença das classes populares na escola e para trabalhar sobre ela como mediação para a aprendizagem. É que os meninos não aprendem. E pior que isso, assumem a repetência, consequência dessa não aprendizagem, como culpa sua. Em pesquisa recente, atingindo todas as Delegacias 
Regionais de Educação do Estado, os alunos entrevistados explicam a sua reprovação: eu não sabia ler (como se a escola não tivesse a responsabilidade de ensinar e ele devesse ser reprovado, porque a escola esperava que, ao chegar, ele já dominasse essa habilidade), eu não gostava de estudar, eu não fazia os deveres de casa, eu bagunçava na escola. Essas são repostas que indicam a introjeção do fracasso e a baixa auto-estima de que muitos deles estão marcados.

Ocupados com outros conhecimentos, não construímos aquele necessário a nossa aproximação dos saberes e das características dos alunos da escola pública. Aqui, vale retomar Guimarães Rosa, para lembrar que, no meio da travessia, embora tentando aí descobrir o real, as pessoas não vêem bem: só estão entretidas com a ideia dos lugares de saída e de chegada, esse último sempre diverso do que esperam, por força da correnteza do rio.

Mas cada um de nós teve um lugar diferente de entrada nessa travessia.

E, quanto a mim, já que me foi dada essa oportunidade, gostaria de rever esse lugar, refletindo um pouco sobre a forma como ele se foi construindo em mim. E me pergunto como, em um momento assim, não me deixar envolver pelas lembranças? como, por uma questão de justiça, não buscar as influências decisivas? como não recuperar as primeiras experiências, retomadas, depois, na Faculdade, em outro patamar, em uma tentativa de análise? como explicar, em mim, essa militância em educação, que não foi só minha mas de meus companheiros, em uma manifestação coletiva?

Migrante de primeira geração, filha de árabe que, como tantos outros, veio fazer a América e aqui permaneceu, aprisionado pelas dificuldades advindas da primeira grande guerra, cedo aprendi sobretudo duas grandes lições: a primeira foi a de conviver com as diferenças, atitude imprescindível ao educador - o pai falava diferente dos outros, pensava diferente dos outros, e tinha histórias onde macacos e onças de nosso imaginário infantil e as experiências com a mala do mascate e depois com a tropa de burros se misturavam a cavernas maravilhosas onde quarenta ladrões se escondiam, a serpentes venenosas do deserto, a marinheiros intrépidos que atravessavam o mar da Arábia, ele mesmo marinheiro de cordas e âncoras tatuadas nos braços - lembrança dos tempos de marinhagem; a outra lição dizia respeito ao tamanho do mundo: Mossul, no norte do Iraque, donde viera, de tão longe era difícil de achar no mapa; além disso, assim que aprendi a ler, filha mais velha, fui estimulada a ler os jornais para ele que, dominando a escrita árabe cristã, herança da cuneiforme dos assírios, não conhecia a ocidental. E eram notícias da guerra civil espanhola e do avanço dos alemães na Europa que, obviamente, eu não entendia, mas dava para saber que o mundo não se reduzia a Itapagipe, embora viver na Ribeira me fosse absolutamente suficiente. E quando descobri Garcia Lorca, eu me perguntava se não teria lido, sem saber, a notícia de sua morte, se é que, àquela época, a morte de um poeta revolucionário poderia ser notícia de jornal. Uma terceira lição veio da influência materna - surpreendentemente, da mocinha da zona rural, alfabetizada sem escola, ajudada por um irmão: o prazer da leitura, que lhe permitiu o conhecimento do mundo urbano, idealizado até, através, sobretudo, de traduções da literatura francesa, muito em voga, na época. Ela me passou esse prazer e eu tive acesso muito cedo às obras de Monteiro Lobato e em seguida a tudo que eu quisesse, sem restrição.

Como alguns outros de minha geração, a primeira escola que conheci era multisseriada. Mais tarde, eu me dei conta de que toda 
classe é multisseriada pelas diferenças de desenvolvimento de aprendizagens que há em seu interior. Só que nem sempre o professor sabe disso. Mas, naquela, a multisseriaçào era explícita e aqueles mais de vinte alunos sentados em torno de uma grande mesa, na sala de jantar, cursavam da $1^{\mathrm{a}}$ à $5^{\mathrm{a}}$ série (assim era então o curso primário na Bahia) sob os cuidados de uma única professora que se desdobrava, se a tanto me ajuda a memória, atendendo os mais atrasados, cobrando mais dos mais velhos,fazendo trabalhos conjuntos, envolvendo a classe inteira, e, aos sábados, sistematicamente, entregando a manhã aos mais adiantados que conduziam as brincadeiras no quintal, o teatro, o canto, os desenhos, as histórias, de que todos participavam. Eram os anos 38, 39, 40 e nesses dois últimos eu vivi a experiência, com dois colegas mais velhos, de pensar, de véspera, o que fazer com a classe e conduzir as atividades dos sábados, sob a supervisão da professora.E eu, enquanto valorizo tal experiência, estranho que há sessenta anos atrás, essa professora, Dona Zaira Meireles Marques, respeitasse o aluno como sujeito de sua aprendizagem e não tivesse tido medo de permitir tal exercício de liberdade. No inicio dos anos oitenta, coordenando, na Faculdade de Educação, por força de questionamentos que me perseguiram todo o tempo, uma pesquisa sobre esse tipo de escola, em 32 municípios baianos, em nenhuma foi encontrada a crença nas condições do aluno que essa professora demonstrara.

E vieram o ginásio e o curso pedagógico, no Colégio Santa Bernadete. Aí eu tive a experiência do contato com a mente aberta de Dr Luis Rogério de Souza, mais tarde meu colega de Departamento na Faculdade de Educação, mas então meu professor por cinco anos e, depois, meu mestre por toda a vida. Com ele, eu aprendi a ver o mundo fora dos cânones, fosse na literatura moderna da geração de 30 e de 45 que as antologias de então ocultavam, não ultrapassando o simbolismo de Alphonsus de Guimarães e de Cruz e Souza; fosse na valorização dos conceitos que, na ciência, expressavam os saltos qualitativos para uma visão nova - e era interessante falar na evolução darwinista em uma escola religiosa, sem ser cerceado pela direção; fosse do ponto de vista religioso, ateu confesso, ante uma classe de adolescentes que o enfrentavam com seus argumentos fracos que ele respeitava, aceitando o debate; fosse do ponto de vista pedagógico, quando ele conseguia traduzir para a língua do aluno a linguagem da ciência, fugindo às aulas expositivas e usando formas concretas para facilitar a apreensão da realidade. Daí me nasceu o gosto de acatar o novo com a curiosidade suficiente para desvelá-lo, sem subestimar a força das posições já solidificadas, das estruturas tácitas, identificadas, depois, por Bohn e Peat, em Ciência, Ordem e Criatividade. Daí o esforço sempre desenvolvido e nem sempre bem sucedido de acompanhar o tempo, de perseguir a contemporaneidade. Daí, o respeito ao aluno, em sua forma de ser, como sujeito de sua aprendizagem. Daí a luta contra o estabelecido, e quantas vezes com quanta ingenuidade, se esse estabelecido rompe com a justiça, rompe com os princípios éticos.

Vieram a vida universitária e a vida profissional a um só tempo, acompanhadas da participação na Ação Católica, movimento de origem belgo-francesa, de caráter progressista, atuante, à época, no meio estudantil e, com ela, a descoberta de teóricos do existen-cialismo cristão, entre eles Gabriel Mareei e Emanoel Mounier; e o exercício sistemático de um método de leitura da realidade que, por certo, serviu de apoio aos trabalhos de educação.

E de novo, no Colégio Santa Bernadete, já professora, a busca, 
com o grupo, da realização de um projeto pedagógico entre cujos méritos estava o de ser uma construção contínua, permanente e coletiva, com acompanhamento sistemático feito pelo conjunto de professores e pela representação de alunos. Era a tentativa de encontrar o real no meio da travessia. Daí nasceram as preocupações com a melhoria da qualidade do ensino, que eu experimentava transferir às aulas do noturno do antigo Instituto Normal da Bahia, depois ICEIA, também minha casa. E iniciava-se, no próprio Santa Bernadete, o exercício democrático da coordenação pedagógica que, mais tarde, me levou ao ensino da Supervisão Educacional na Faculdade de Educação

Esse, portanto, o ponto de entrada no rio.

Não se tratava, então, de reunir um referencial teórico, estudar e dar aulas.Tratava-se de socializar uma prática coletiva, que foi sendo construída por quase uma década, e, naquele momento, não contava com uma bibliografia específica produzida no contexto de nossa realidade. Tratava-se de fazer entender que aquele processo de vários nomes, substituídos uns pelos outros até por questões ideológicas - coordenação pedagógica, orientação pedagógica, assistência pedagógica ou supervisão educacional - aquele processo para apoiar o professor e o aluno na sala de aula, deveria ser um trabalho coletivo e contextualizado de diagnóstico, planejamento, acompanhamento e avaliação cias atividades de ensino e aprendizagem, considerados os controles burocráticos como suporte. Tratava-se de fazer também coletivo o trabalho da Faculdade na formação desse profissional equivocadamente nominado especialista E criou-se o Núcleo de Supervisão. Jandyra Simões, Nilza Maria Souza Santos e eu com os, então, alunos feitos monitores, Sônia Bamberg, Magaly Figueredo, Adélia Luíza Portela e Raimundo Lopes (a quem aqui homenageio e, neles, a todos - tantos que nos permitiram aprender e crescer) todos juntos iniciamos o esforço de fundamentar a prática com a busca de referencial bibliográfico conveniente. Esse primeiro grupo foi ampliado com a participação de ElzaAnders, Marilene Santil Santos e, mais tarde, Regina Antoniazzi, Maria das Graças Galvão de Souza e Iracy Alves. Impossível esquecer o sem número de alunos que iam se substituindo ao final de cada ano letivo. Impossível também esquecer outros professores que, sem serem da Supervisão, integraram o Núcleo, até fisicamente, com carteira e armário: Haidê Correia da Silva e Coriolinda Vasconcelos de Carvalho que conosco trabalharam em pesquisas e programas de extensão e Odile Lima que, professora e pesquisadora, nos ensinou a todos a respeitar os dados, a perseguir os objetivos, a rever posições sedimentadas, a olhar com profundidade para o objeto de estudo, a exigir de si mais do que exigia dos outros. A ela, distante do nosso convívio permanente por circunstâncias de saúde,nesse momento, as homenagens dessa geração que hoje eu aqui represento.

A busca de um referencial bibliográfico pelo Núcleo de Supervisão encontrou respostas.

Até 1970, quando a formação do supervisor passou a ser responsabilidade dos Cursos de Pedagogia, a bibliografia usada pelos que trabalhavam no setor e que se relacionava com o então ensino primário, cujo foco principal era o sistema educacional e não a escola, essa bibliografia não era nacional, mas produzida no contexto da sociedade americana com as marcas do pragmatismo e do tecnicismo que lhe são característicos; e a capacitação dos técnicos dos órgãos centrais do sistema realizava-se nas Universidades dos Estados Unidos, transplantando-se o processo diretamente para as escolas brasileiras, no bojo dos acordos MEC-USAID. 
Ao contrário, os profissionais do então Ensino Médio, que tinham como foco a sala de aula e o processo ensino/aprendizagem não usavam uma bibliografia específica de Supervisão. Agregavam, à inspiração europeia dos métodos ativos do movimento da Escola Nova, dois conjuntos de idéias: a influência, no movimento estudantil, do pensamento marxiano, já presente nas Universidades, bem como elementos do existencialismo cristão, por influência, também nas universidades, do movimento da Ação Católica, extremamente atuante no meio estudantil, de onde se recrutavam os professores. Ao lado disso, já se começavam a divulgar as pesquisas de Piaget, cujas idéias, mais tarde, serviram de suporte para muitos trabalhos na área.

A partir de 1970, foram publicadas obras escritas por professores brasileiros sobre o assunto. Muitos repetiam a fórmula americana; aqueles que estavam mais ligados ao que se pode chamar de escola europeia e que realizavam algumas experiências interessantes nos anos sessenta, ou até desde antes, publicavam seus resultados em revistas de circulação nacional. Pode-se, porém, afirmar que essa bibliografia inicial é mais descritiva do que analítica, o que se modifica no final dos anos setenta e nos anos oitenta.

Dois fatores contribuíram principalmente para essa mudança. De um lado, o movimento político da categoria de supervisores realizou Encontros Nacionais de Supervisão, provocando uma produção significativa, cujo teor analisa o contexto educacional brasileiro e a função supervisora no interior da escola e do sistema educacional, com uma visão fortemente crítica e um respaldo teórico convincente.

Ocorreu o mesmo com a produção resultante dos cursos de Pós-graduação em Educação: surgiram, sobre o tema, dissertações ora de caráter histórico, ora de caráter empírico, com referencial teórico marxiano e gramsciano, entre outros, oferecendo recursos para o aprofundamento e a crítica da função, em seu caráter de expropriação do trabalho do professor, no bojo, inclusive, do debate sobre a formação do educador, com vistas a mudanças nos cursos de Pedagogia.

Em momentos diversos, esse material foi analisado nos cursos. $E$ analisadas foram também a postura profissional do supervisor, na maioria das vezes assumindo-se como burocrata dentro do sistema e dentro da escola; e a perda de espaço desse profissional, seja no sistema estadual seja nos sistemas municipais de Educação, portanto ausente da escola pública. Há uma decisão política do Estado a ser analisada. Há o espaço a ser corretamente ocupado. Há a lacuna sentida e reclamada pelos professores.

Em pesquisa recente realizada no Estado da Bahia, $80 \%$ de professores de escolas públicas entrevistados pediram um acompanhamento de caráter contínuo e coletivo dentro da escola, realizado por uma coordenação pedagógica que pode ser exercida pelo Diretor, por um professor, de preferência escolhido pelos demais e mantendo-se uma parte do horário com regência de classe, por um supervisor, seja quem for com um preparo específico, isto é, com o olhar instrumentalizado para apreender a teia de relações em que se enredam professores e alunos, no interior da sala de aula, onde não se consegue construir conhecimento e, no grupo de docentes, os resultados sejam discutidos e se tentem novos caminhos, até os propostos nas capacitações que os professores, isolados em suas salas, terminam por abandonar, voltando às formas tradicionais de ensino. Na ausência do apoio da coordenação, muitos professores, compreendendo que melhores condições de trabalho incluem o direito a tempo e espaço condizentes 
à realização de um trabalho criativo, já começam a reunír-se em sua própria escola, fora do horário de AC que perdeu o significado, ou reúnem-se a professores de diferentes escolas, para que esse processo de interlocução possa se estabelece.

Como se pode ver, ainda estou na travessia, esperando que o meu ponto de chegada, seja ele qual for, encontre a supervisão, meu objeto de estudo na Faculdade de Educação, mais uma vez chamada de coordenação pedagógica, apoiando professores e alunos da escola pública, na identificação da qualidade de ensino que lhes diz respeito. $\mathrm{E}$ que isso resulte na democratização da aprendizagem dos alunos, de todos os alunos.

Senhor Reitor.em meu nome próprio e em nome da minha geração, muito obrigada. 